\title{
The Optimized Use of Gas Chromatography-Mass Spectrometry and High Performance Liquid Chromatography to Analyse the Serum Bile Acids of Patients with Metabolic Cholestasis and Peroxisomal Disorders
}

\author{
Florence Courillon ${ }^{1}$, Marie Françoise Gerhardt ${ }^{1}$, Anne Myara ${ }^{1}$, Francis Rocchiccioli ${ }^{2}$ and François Trivin ${ }^{1-3}$ \\ ${ }^{1}$ Service de Biochimie, Hôpital Saint-Joseph, Paris, France \\ 2 Inserm U342, Hôpital Saint Vincent de Paul, Paris, France \\ 3 Biochimie Clinique, Faculté de Pharmacie, Tours, France
}

\begin{abstract}
Summary: We have measured the bile acids in human serum as methyl ester-trimethylsilyl ethers by gas chromatography-mass spectrometry (GC-MS) using an electron ionization procedure. The overall method was validated and the detection limit $(0.4 \mu \mathrm{mol} / \mathrm{l})$, linearity $(2-30 \mu \mathrm{mol} / \mathrm{l})$, intra-day and inter-day precision, accuracy and recovery (96.2\% for nor-23-deoxycholic acid as internal standard) were measured. Serum $\mathrm{C}_{24}$-bile acids profiles from 43 cholestatic patients were measured by GC-MS and by HPLC. The results obtained with the two methods were well correlated and the criteria for selecting either HPLC or GC-MS identified. The serum $\mathrm{C}_{24-}$ and $\mathrm{C}_{27}$-bile acids and $\mathrm{C}_{29}$ dicarboxylic bile acid profiles for patients with generalized peroxisomal deficiencies, like Zellweger syndrome $(\mathrm{n}=5)$, neonatal adrenoleukodystrophy $(\mathrm{n}=1)$, infantile Refsum disease $(\mathrm{n}=2)$ and from a single peroxisomal deficiency $(n=1)$ were also measured by GC-MS.
\end{abstract}

\section{Introduction}

Primary $\mathrm{C}_{24}$-bile acids like cholic acid and chenodeoxycholic acid are end products of the oxidative degradation of cholesterol in the liver. This catabolism involves both the sterol nucleus, with the synthesis of $\mathrm{C}_{27}$-bile acids intermediates like trihydroxycholestanoic acid and dihydroxycholestanoic acid, and the shortening of their side chain 8 to 5 carbons by $\beta$-oxidation. This last step is located in peroxisomes (1). Glyco- and tauro-conjugated cholic acid and chenodeoxycholic acid are then secreted into the bile and released into the intestine, where bacterial $7 \alpha$-dehydroxylation of cholic acid and chenodeoxycholic acid occurs to produce secondary bile acids like deoxycholic acid and lithocholic acid and epimerization of chenodeoxycholic acid to form ursodeoxycholic acid (2). Biochemical abnormalities occuring during cholestasis or peroxisomal enzymatic defects require the separation, identification and a quantitative measurement of the serum bile acids profile. Gas chromatography (GC) (3) and HPLC (4) methods are the mainstays for serum bile acids profile analysis. The high boiling points of conjugated bile acids make deconjugation and derivatization necessary for GC analysis. Conjugated bile acids have been assayed directly by HPLC, but UV detection is limited by the poor absorptivity of conjugated and unconjugated bile acids (5). Sensitivity has been improved using pre- or post-column derivatization and more sensitive fluorimetric or electrochemical detectors (6). GC and HPLC require efficient internal standards and reference bile acids were not always available. Mass spectrometry (MS), equipped with GC-MS (7) or HPLC-MS (8) seems thus to be the efficient tool for identification of bile acids during physiopathological situations. Fast atom bombardment-mass spectrometry (FAB MS) (9), fast atom bombardment tandem mass spectrometry (FAB MS/MS) (10), HPLC/FAB MS (11) and negative ion chemical ionization-mass spectrometry (NICI/MS) (12) have been described for the rapid screening of bile acids particular to enzyme defects of biosynthesis. The present study describes a validated GC-MS method. We have correlated serum $\mathrm{C}_{24}$-bile acids profiles from cholestatic patients using both the GC-MS and HPLC methods. Bile acids profiles of patients with generalized or single peroxisomal disorders have been investigated.

\section{Materials and Methods}

Materials

Reagents used were analytical grade and the water was ultra-pure (resistance $18.2 \mathrm{M} \Omega / \mathrm{cm}$ ). The bile acids already mentioned, nor23-deoxycholic acid and $5 \alpha$-cholestane were purchased from Steraloids, Inc., (Wilton, N. H., USA). Cholylglycine hydrolase (EC 3.5.1.24), (ref C 4018), was purchased from Sigma Chemical Co. (St. Louis, MO, USA). Bond Elut ${ }^{\circledR} \mathrm{C}_{18}$ was purchased from Analytical International (Harbor City, CA, USA) and Lipidex $1000^{\circledR}$ from Packard Instrument (Groningen, Netherlands). Methanolichydrochloric acid was purchased from Supelco (Bellefonte, USA) and Tri-Sil ${ }^{\circledR}$ reagent (ref 49001) from Pierce (Rockford, IL, USA).

\section{Sample preparation}

Glyco- and tauro-conjugated bile acids were removed from their binding proteins and extracted for HPLC (13). Glyco- and tauro- 
conjugated bile acids were deconjugated, removed from their binding proteins, extracted and derivatized for GC-MS. The bile acids of $0.3 \mathrm{ml}$ serum were deconjugated with cholylglycine hydrolase $(60 \mathrm{U})$ in $0.2 \mathrm{~mol} / 1$ sodium acetate buffer $\mathrm{pH} 5.6(2 \mathrm{ml})(20$ hours, $37^{\circ} \mathrm{C}$ ) (14). Bile acids were released from proteins with $0.1 \mathrm{~mol} / \mathrm{l}$ $\mathrm{NaOH}\left(1.2 \mathrm{ml}, 64^{\circ} \mathrm{C}, 20 \mathrm{~min}\right)$. Nor-23-deoxycholic acid $(10 \mathrm{nmol})$ was then added. Bile acids were extracted by adsorption onto Bond Elut ${ }^{3} \quad \mathrm{C}_{18}$ cartridges and were eluted with methanol:water $(10+90$, by vol $)(5 \mathrm{ml})$, methanol:water $(30+70$, by vol $)(5 \mathrm{ml})$ and methanol $(2 \times 5 \mathrm{ml})$. The eluates were evaporated. The residues were dissolved in $2 \mathrm{ml} 0.15 \mathrm{~mol} / \mathrm{l}$ phosphate buffer ( $\mathrm{pH} 5.8$ ) and brought to $\mathrm{pH}$ 4.0. This mixture was then passed through a Lipidex $1000^{\circledR}$ cartridge. Bile acids were eluted with water-acetic acid (pH 4.0) $(2 \times 5 \mathrm{ml})$ and water-hydrochloric acid ( $\mathrm{pH} 4.0)$ $(2 \times 5 \mathrm{ml})$. These acid eluates were kept for a further step. Bile acids were eluted from the Lipidex $1000^{\circledR}$ cartridge with methanol:water $(68+32$, by vol $)(10 \mathrm{ml})$ and methanol $(10 \mathrm{ml})$. These Lipidex ${ }^{\circledR}$-methanol-eluates were kept for a further step. The acid eluates were run onto a new Bond Elut ${ }^{\circledR}$ cartridge, and bile acids were eluted with methanol:water $(10+90$,by vol) $(5 \mathrm{ml})$, methanol:water $\left(30+70\right.$, by vol) $(5 \mathrm{ml})$ and methanol $(8 \mathrm{ml})$ (Bond Elut ${ }^{\circledR}$ methanol-eluates). The Lipidex ${ }^{\circledR}$-methanol-eluates and Bond Elut ${ }^{\circledR}$-methanol-eluates were pooled and evaporated. $5 \alpha$-Cholestane $(10 \mathrm{nmol})$ was added. Bile acids were methylated with methanolic-hydrochloric acid $(2 \mathrm{ml})\left(25^{\circ} \mathrm{C}, 8 \mathrm{~h}\right)$. The mixture was evaporated, trimethylsilylated with Tri-Sil ${ }^{\circledR}$ reagent $\left(200 \mu \mathrm{l}, 60^{\circ} \mathrm{C}\right.$, $15 \mathrm{~min}$ ) and evaporated. Finally, the bile acids were dissolved in hexane $(200 \mu \mathrm{l})$.

\section{Chromatography}

GC-MS analysis was performed on an HP 5890 series II gas chromatograph (Hewlett-Packard, Sunnyvale, CA, USA) equipped with an HP-5 MS capillary column $(30 \mathrm{~m} \times 0.25 \mathrm{~mm}$ I. D., $0.25 \mu \mathrm{m}$ film thickness ref number 19091S-433) which was connected to an HP 5971 A mass spectrometer. Helium was the carrier gas (flow rate : $1.8 \mathrm{ml} / \mathrm{min}$ ); the oven temperature was $50^{\circ} \mathrm{C}$ for 2 minutes, increased to $220^{\circ} \mathrm{C}\left(20^{\circ} \mathrm{C} / \mathrm{min}\right)$, then $295^{\circ} \mathrm{C}\left(2^{\circ} \mathrm{C} / \mathrm{min}\right)$, and was $295^{\circ} \mathrm{C}$ for $10 \mathrm{~min}$; the temperature was $250^{\circ} \mathrm{C}, 280^{\circ} \mathrm{C}$ and $180^{\circ} \mathrm{C}$ for the injection port, the transfer line and the ion-source, respectively. The MS system was run in electron impact mode with 70 $\mathrm{eV}$ electron energy. The methylether-trimethylsilylesters of bile acids in hexane $(1 \mu 1)$ were injected manually in splitless mode. $5 \alpha$-Cholestane and the bile acids were identified by their R compound values calculated with reference to nor-23-deoxycholic acid (tab. 1) and their mass spectrum data were taken from commercial reference compounds and tables (15). $\mathrm{C}_{27}$-bile acids, like trihydroxycholestanoic acid (THCA), dihydroxycholestanoic acid, or varanic acid (THCA-24-ol) and $\mathrm{C}_{29}$ dicarboxylic bile acid, were not available commercially although some standard $\mathrm{C}_{27}$-bile acids were syn-

Tab. 1 Retention times of $5 \alpha$-cholestane and bile acids $\left(R_{\text {compound }}\right.$ values) related to nor-23-deoxycholic acid and correlation coefficients of standard curves

\begin{tabular}{lll}
\hline Analyte & $\begin{array}{l}\text { Relative } \\
\text { retention } \\
\text { time }\end{array}$ & $\begin{array}{l}\text { Correlation } \\
\text { coefficient } \\
\text { of standard } \\
\text { curves }\end{array}$ \\
\hline $5 \alpha$-Cholestane & 0.800 & \\
nor-23-Deoxycholic acid & 1.000 & 0.997 \\
Lithocholic acid & 1.041 & 0.997 \\
Deoxycholic acid & 1.093 & 0.997 \\
Chenodeoxycholic acid & 1.111 & 0.997 \\
Cholic acid & 1.117 & 0.997 \\
Ursodeoxycholic acid & 1.152 & 0.996 \\
Trihydroxycholestanoic acid & 1.298 & \\
Dihydroxycholestanoic acid & 1.298 & \\
Varanic acid & 1.414 & \\
C29-Dicarboxylic bile acid & 1.778 & \\
\hline
\end{tabular}

thesized (16). The $\mathrm{C}_{27}$-bile acids and $\mathrm{C}_{29}$ dicarboxylic bile acid were identified by their $R$ compound values (tab. 1) and their mass spectrum data were compared to reference compound tables (15). $\mathrm{C}_{24}$-bile acids were quantified by measuring the area under the peak using the internal standard method with $5 \alpha$-cholestane and $\mathrm{C}_{27}$-bile acids and $\mathrm{C}_{29}$ dicarboxylic bile acid with the standard curve for cholic acid.

\section{Analytical validation of the GC-MS method}

Calibration curves were constructed using concentrations of 2,4 , $10,20,30 \mu \mathrm{mol} / 1$. The detection limit was determined as the concentration of bile acids at which the signal-to-noise ratio was $\geq 3$, with a coefficient of variation less than $15 \%(n=5)$. The precision (correlation coefficients) and measured concentration (mean \pm standard deviation) were determined using stock serum with low $(n=5)$, medium $(n=5)$, and high concentrations $(n=5)$ for intra-day precision and on 5 subsequent days for inter-day precision. Accuracy and recovery data were obtained with serum added with working standards of bile acids $(2,4,10,20$ and $30 \mu \mathrm{mol} / \mathrm{l})$ $(\mathrm{n}=5)$. Recovery studies were also performed by assaying human cholestatic serum $(n=43)$ containing nor-23-deoxycholic acid $(10 \mathrm{nmol})$.

Total serum bile acid analysis

Total bile acids were measured using the $3 \alpha$-hydroxysteroid dehydrogenase method (Enzabile ${ }^{\circledR}$; Nycomed, Oslo, Norway).

\section{Comparison of Enzabile ${ }^{\circledR}$, GC-MS and HPLC procedures}

Samples from patients suffering from various cholestatic diseases $(n=43)$, with or without ursodeoxycholic acid treatment, were analysed. The data for total bile acids measured by Enzabile ${ }^{\circledR}$ and calculated from GC-MS and HPLC by adding the specific bile acids identified were compared as were the bile acids profiles obtained with the GC-MS and HPLC methods. Statistical analysis was performed with the Student's test and $\mathrm{p}<0.05$ was used as the criterion of statistical significance.

Measurement of $\mathrm{C}_{24-}$ and $\mathrm{C}_{27}$-bile acids and $\mathrm{C}_{29}$ dicarboxylic bile acid by GC-MS

Patients with generalized peroxisomal deficiencies, such as Zellweger syndrome $(\mathrm{n}=5)$, neonatal adrenoleukodystrophy $(\mathrm{n}=1)$ and infantile Refsum disease $(\mathrm{n}=2)$ and a single peroxisomal enzyme deficiency $(n=1)$ as bifunctional protein or thiolase activity were analysed.

\section{Results}

\section{Validation of the GC-MS procedure}

The detection limit was $0.4 \mu \mathrm{mol} / 1$. The method was linear over the range $2-30 \mu \mathrm{mol} / \mathrm{l}$.The correlation coefficients of standard curves were 0.997 and 0.996 , respectively (tab. 1). The intra-day precisions were $1.91-5.92 \%, 1.18-4.71 \%, 0.81-4.39 \%$ for the low, medium and high concentrations, respectively and the equivalent inter-day precisions were $2.16-7.45 \%$, $3.57-9,52 \%$ and $2.14-4.44 \%$. The overall values of recoveries of standard bile acids added to serum samples were $82.6 \%-111.3 \%$ for $2 \mu \mathrm{mol} / 1$ and were $99.5 \%-102.7 \%$ for $30 \mu \mathrm{mol} / 1$. Recovery of nor-23-deoxycholic acid was $96.2 \pm 3.1 \%(n=43)$. 
Tab. 2 Correlation coefficients and linear regression for comparison of high performance liquid chromatography (HPLC), gas chro-

matography/ mass spectrometry (GC-MS) and the enzymatic method (Enzabile ${ }^{\circledR}$ )

\begin{tabular}{llrrr}
\hline Analyte & Compared & $\mathrm{n}$ & $\mathrm{r}$ & $\mathrm{y}$ \\
\hline Total $\mathrm{C}_{24}$ bile acids & GC-MS/ HPLC & 43 & 0.990 & $1.00 \mathrm{x}+8.58$ \\
& HPLC/ Enzabile & 22 & 0.986 & $0.79 \mathrm{x}+4.45$ \\
& GC-MS/ Enzabile & 22 & 0.998 & $0.87 \mathrm{x}+6.18$ \\
Cholic acid & GC-MS/ HPLC & 43 & 0.993 & $0.98 \mathrm{x}-0.66$ \\
Chenodeoxycholic acid & GC-MS/ HPLC & 41 & 0.980 & $1.03 \mathrm{x}+1.25$ \\
Deoxycholic acid & GC-MS/ HPLC & 28 & 0.916 & $0.88 \mathrm{x}+0.32$ \\
Lithocholic acid & GC-MS/ HPLC & 21 & $0.593^{*}$ & $0.48 \mathrm{x}+0.73$ \\
Ursodeoxycholic acid & GC-MS/ HPLC & 22 & 0.988 & $0.91 \mathrm{x}+8.03$ \\
\hline
\end{tabular}

$* \mathrm{p}<0.05$

\section{Comparison of HPLC and GC-MS}

The correlation coefficients and linear regression for total and individual $\mathrm{C}_{24}$-bile acids are given in table 2 .

\section{GC-MS analysis of atypical bile acids}

The following mean ratios were calculated for patients with peroxisomal disorders:
(a) $\frac{\mathrm{C}_{27} \text {-bile acids }+\mathrm{C}_{29} \text { dicarboxylic bile acid }}{\text { total bile acids }}=86 \%$
(b) $\frac{\text { trihydroxycholestanoic acid }}{\text { cholic acid }}=0.6$ to 18
(c) $\frac{\text { dihydroxycholestanoic acid }}{\text { chenodeoxycholic acid }}=0.39$ to 5.43

(d)

trihydroxycholestanoic acid $+\mathrm{C}_{29}$ dicarboxylic bile acid cholic acid

$$
\begin{aligned}
& =1.71 \text { to } 34.6^{*} \\
& * d>b \text { in } 78 \% \text { of the patients }
\end{aligned}
$$

Accumulation of varanic acid was found in the serum of a patient with the single peroxisomal enzyme deficiency.

\section{Discussion}

Extraction of serum bile acids should ensure the selective recovery of bile acids with polarities between those of lithocholic acid and cholic acid and remove any compounds likely to interfere with their spectral properties in HPLC-UV or their structural data in GC-MS analyses. Serum bile acids were usually extracted by liquid-solid phase adsorptions as first described by Dyfverman \& Sjövall (17), and Setchell \& Matsui (18). Although a recent study has pointed out the superiority of triethylamine sulphate for the safety against potential degradation of Bond Elut ${ }^{\circledR}$ cartridges by alkaline eluates, we have not worried about this question (19). The recoveries of total bile acids and the overall analytical properties of the GC-MS method used were satisfactory. The total bile acids concentrations obtained by the Enzabile ${ }^{\circledR}$ procedure were well correlated with the values obtained with the GC-MS and HPLC processes. The concentrations of cholic acid, chenodeoxycholic acid and deoxycholic acid measured by HPLC and by GC-MS were well correlated, despite the bias introduced by HPLC not measuring physiological unconjugated bile acids which does not increase in cholestatic diseases (20) and sulphated bile acids were not measured by either methods. These results indicate no detectable loss of bile acids during the enzymatic or derivatization steps. Impurities and matrix constituents with absorptivity at $200 \mathrm{~nm}$ affected the identification of bile acids by HPLC, generating unidentified peaks even at trace level; the low molar absorbances of bile acids in the UV spectrum were also disturbing factors. Because of the limit of sensitivity for HPLC, bile acids must be quantified by GC-MS when the concentration is lower than $1 \mu \mathrm{mol} / 1$. Ursodeoxycholic acid is currently used to treat cholestatic liver diseases (21) and concentrations measured by GC-MS and HPLC methods were well correlated. This optimized sample preparation allowed us to measure, for the same patient, the serum composition and conjugation profile of bile acids with both the HPLC and GC-MS methods. The system is also efficient in that similar reagents and preparation procedures are used for both methods. The biochemical screening for a peroxisomal disorder may include a serum bile acids profile $(22,23)$. Our ratio (d), higher than ratio (b) (24) usually calculated, can be added. We have developed a reliable, reproducible and relatively easy GC-MS method, well correlated with HPLC, for the determination of serum bile acid profiles. FAB MS/MS was very efficient for a rapid identification of bile acids without multi-step preparation of the sample, but isomers are not separated and this method is not quantitative (10). A quantitative composition and conjugation profile of bile acids provides information on bile acids metabolism, such as detoxifying pathways or peroxisomal defects that occur during liver diseases.

\section{Acknowledgements}

We thank E. Ungar, Y. Khodja and E. Bouvier for technical assistance. 


\section{References}

1. Russel DW, Setchell KDR. Bile acid biosynthesis. Biochemistry $1992 ; 31: 4737-49$.

2. Hofmann AF. Bile acids. In: Arias IM, Boyer JL, Fausto N, Jakoby WB, Schachter DA, Schafritz DA, editors. The liver: biology and pathobiology. 3rd ed. New York: Raven Press, Ltd, 1994:677-718.

3. Karlaganis G, Paumgartner G. Analysis of bile acids in serum and bile by capillary column gas-liquid chromatography. $\mathrm{J}$ Lipid Res 1978; 19:771-4.

4. Scalia S, Pazzi P. HPLC assay of conjugated bile acids in human fluids using on-line sample pretreatment on a standard isocratic chromatograph. Clin Chim Acta 1994; 224:181-90.

5. Rossi SS, Converse JL, Hofmann AF. High pressure liquid chromatographic analysis of conjugated bile acids in human bile: simultaneous resolution of sulfated and unsulfated lithocholyl amidates and the common conjugated bile acids. J Lipid Res 1987; 28:589-95.

6. Sakakura H, Suzuki M, Kimura N, Takeda H, Nagata S, Maeda $\mathrm{M}$ Simultaneous determination of bile acids in rat bile and serum by high-performance liquid chromatography. J Chromatogr B 1993; 621:123-31.

7. Batta AK, Arora R, Salen G, Tint S, Eskreis D, Katz S. Characterization of serum and urinary bile acids in patients with primary biliary cirrhosis by gas-liquid chromatography-mass spectrometry: effect of ursodeoxycholic acid treatment. J Lipid Res 1989; 30:1953-62.

8. Roda A, Cerrè C, Simoni P, Polimeni C, Vaccari C, Pistillo A. Determination of free and amidated bile acids by high performance liquid chromatogaphy with evaporative light-scattering mass detection. J Lipid Res 1992; 33:1393-402.

9. Setchell KDR, Suchy FJ, Welsh MB, Zimmer-Nechemias L, Heibi J, Balistreri WF. Delta4-3-oxosteroid-5 $\beta$-reductase deficiency described in identical twins with neonatal hepatitis. A new inborn error in bile acid synthesis. J Clin Invest 1988; 82:2148-57.

10. Libert R, Hermans D, Draye JP, Van Hoof F, Sokal E, de Hoffmann $E$. Bile acids and conjugates identified in metabolic disorders by fast atom bombardment and tandem mass spectrometry. Clin Chem 1991; 37:2102-10.

11. Evans JE, Ghosh A, Evans BA, Natowicz MR. Screening techniques for the detection of inborn errors of bile acid metabolism by direct injection and micro-high performance liquid chromatography-continuous flow/fast atom bombardment mass spectrometry. Biol Mass Spectrom 1993; 22:331-7.

12. Goto J, Miura H, Nambara T. Determination of $5 \beta$-cholestanoic acids in human urine by gas chromatography-mass spectrometry with negative ion chemical ionization detection. $\mathrm{J}$ Chromatogr B 1989; 493:245-55.
13. Labbé D, Gerhardt MF, Myara A, Vercambre C, Trivin F. High-performance liquid chromatographic determination of tauro- and glyco-conjugated bile acids in human serum. $\mathrm{J}$ Chromatogr B 1989; 490:275-84.

14. Nair PP. Enzymatic cleavage of bile acid conjugates. In: Schiff L, Carey JB, Dietschy Jr and JM, editors. Bile salt metabolism. Springfield: Thomas C, 1969:172-83.

15. Lawson A, Setchell KDR. Mass spectrometry of bile acids. In: Setchell KDR, Kristchevsky D, Nair PP, editors.The bile acids, methods and applications. New York: Plenum Press, 1988; $4: 167-267$.

16. Kurosawa T, Sato M, Kikuchi F, Tazawa Y, Tohma M. Capillary gas chromatographic determination of $\mathrm{C} 27$-bile acids in biological samples and its application to the urine of a patient with Zellweger syndrome. Anal Sci 1996; 12:841-8.

17. Dyfverman A, Sjövall J. Liquid-gel extraction of bile acids. In: Paumgartner G, Stiehl A. Gerok W, editors. Proceedings of 26th Falk Symposium. Biological effects of bile acids. Lancaster, UK: MTP Press Ltd, 1978:281-6.

18. Setchell KDR, Matsui A. Serum bile acid analysis. Clin Chim Acta $1983 ; 127: 1-17$.

19. Rodrigues CMP, Setchell KDR. Performance characteristics of reverse-phase bonded silica cartridges for serum bile acid extraction. Biomed Chromatogr 1996; 10:1-5.

20. Bolt MJG, Stellaard F, Sitrin MD, Paumgartner G: Serum unconjugated bile acids in patients with small bowel bacterial overgrowth. Clin Chim Acta 1989; 181: 87-101.

21. Poupon RE, Balkau B, Eschwege E, Poupon R: A multicenter, controlled trial of ursodiol for the treatment of primary biliairy cirrhosis. N Engl J Med 1991; 324:1548-54.

22. Wanders RJA, Van Roermund CWT, Schutgens RBH. The inborn errors of peroxisomal $\beta$-oxidation: a review. J Inher Metab Dis 1990; 13:4-36.

23. Verhoeven NM, Kulik W, Van Den Heuvel CMM, Jakobs C. Pre-and postnatal diagnosis of peroxisomal disorders using stable-isotope dilution gas chromatography-mass spectrometry. J Inher Metab Dis 1995; 18:45-60.

24. Stellaard F, Langelaar SA, Kok RM, Jakobs C. Determination of plasma bile acids by capillary gas-liquid chromatographyelectron capture negative ionization mass fragmentography. J Lipid Res 1989; 30:1647-52.

Received June 27/October 2, 1997

Corresponding author: Florence Courillon, Service de Biochimie, Hôpital Saint-Joseph, 185, rue Raymond Losserand,

F-75674 Paris Cedex 14, France

Tel: + 33144123465 , Fax: + 33144123244 